Article

\title{
Evaluation of Morphological Changes in Grapes Coated with a Biosurfactant Extract Obtained from Corn Steep Liquor
}

\author{
Andrea Martínez-Arcos ${ }^{1}$, Alejandro López-Prieto ${ }^{1}\left(\mathbb{D}\right.$, Lorena Rodríguez-López ${ }^{1}{ }^{\circledR}$, Benita Pérez-Cid ${ }^{1,2}$, \\ Xanel Vecino ${ }^{1}$ (D) Ana Belén Moldes ${ }^{1}$ (D) and José Manuel Cruz ${ }^{1, *(D)}$ \\ 1 CINTECX, Chemical Engineering Department, University of Vigo, 36310 Vigo, Spain; \\ andrea.martinez.arcos@uvigo.es (A.M.-A.); alexlopez@uvigo.es (A.L.-P.); lorena@uvigo.es (L.R.-L.); \\ benita@uvigo.es (B.P.-C.); xanel.vecino@uvigo.es (X.V.); amoldes@uvigo.es (A.B.M.) \\ 2 Analytical Chemistry, Nutrition and Bromatology Department, Faculty of Chemistry, Campus As \\ Lagoas-Marcosende, University of Vigo, 36310 Vigo, Spain \\ * Correspondence: jmcruz@uvigo.es
}

Citation: Martínez-Arcos, A.; López-Prieto, A.; Rodríguez-López, L.; Pérez-Cid, B.; Vecino, X.; Moldes, A.B.; Cruz, J.M. Evaluation of Morphological Changes in Grapes Coated with a Biosurfactant Extract Obtained from Corn Steep Liquor. Appl. Sci. 2021, 11, 5904. https:// doi.org/10.3390/app11135904

Academic Editors: Xana

Álvarez Bermúdez and María Ángeles Cancela Carral

Received: 21 May 2021

Accepted: 22 June 2021

Published: 25 June 2021

Publisher's Note: MDPI stays neutra with regard to jurisdictional claims in published maps and institutional affiliations.

Copyright: (c) 2021 by the authors. Licensee MDPI, Basel, Switzerland. This article is an open access article distributed under the terms and conditions of the Creative Commons Attribution (CC BY) license (https:/ / creativecommons.org/licenses/by/ $4.0 /)$.
Featured Application: Biosurfactant extract from corn steep liquor as a natural preservative agent in food matrixes.

Abstract: In this work, grapes were coated with a multifunctional biosurfactant extract obtained from corn steep liquor after liquid-liquid extraction with ethyl acetate. This biosurfactant extract has been demonstrated to not only possess a surfactant capacity but also antimicrobial activity. Hence, it could be an excellent preservative for fruits, as it is more biodegradable and more biocompatible than chemically synthetized preservatives. However, before applying this biosurfactant as a preservative on fruits, it is necessary to study the changes in the surface properties of fruits produced by the addition of this bioactive compound. Therefore, in this work, grapes coated with an aqueous solution containing $1 \mathrm{~g} / \mathrm{L}$ of the biosurfactant extract were subjected to surface analysis using non-invasive technologies, including profilometry. 2D digital photographs of the surface and parametric roughness of grapes were obtained. They revealed that the biosurfactant extract decreased the roughness of the grape surface compared with non-coated grapes and reduced the changes in the shape of the grapes over time. Moreover, it was observed that the biosurfactant extract increased the hydrophobicity of the grape surface observing higher contact angle compared with non-coated grapes.

Keywords: grapes; biosurfactant; roughness; perimeter; shape; contact angle

\section{Introduction}

Biosurfactants are surface-active compounds produced by microorganisms with similar properties to chemical surfactants, but with a composition comparable to those compounds included in living cell membranes, which are advantageous properties in terms of biocompatibility and food safety. Thus, biosurfactants are composed of lipids, sugars, and/or amino acids, which makes them more biodegradable and less toxic than their chemical homologs [1]. In addition, some of these biosurfactants possess an important bactericide and fungicide capacity [2-4], making them very interesting materials to be used in the food industry as preservatives in order to increase the shelf-life of fruits, which can quickly spoil. For instance, Khedher et al. [4] reported that the biosurfactant extract produced by Bacillus subtillis V26 at concentrations of $2 \mathrm{~g} / \mathrm{L}$ inhibits Botrytis cinerea, which produces the gray mold in grapes and tomato leaves. This biosurfactant extract swelled and deformed the fungal hyphae. In the same study, the authors also reported that the biosurfactant extract act as an insecticide against Tuta absoluta larvae, causing histological damage in the larval midgut. Kourmentza et al. [5] also found that lipopeptide biosurfactants produced by Bacillus sp. showed high antifungal activity against food-relevant 
fungi, such as Paecilomyces variotti and Byssochlamys fulva, at concentrations lower than their toxicity level, suggesting their application for extending the shelf-life of food products.

However, the major drawback to the industrial application of biosurfactants is their higher cost in comparison with chemically synthetized surfactants and preservatives, as they are usually produced by biotechnological processes under controlled conditions [6-8]. Hence, for the realistic incorporation of biosurfactants into industrial formulations and products, it is necessary to work on the production of more cost-competitive biosurfactants. From this point of view, the biosurfactant extract obtained from corn steep liquor (CSL) could be an interesting alternative to chemically synthetized surfactants and preservatives, as it is spontaneously produced in corn steep liquor during the steeping step occurring in the corn milling industry, saving the cost of the biotechnological process $[9,10]$. Regarding the characteristics of this biosurfactant extract, it has been demonstrated that it is a lipopeptide produced by a Bacillus [11-13], composed of C16-C18 fatty acids and amino acids containing glutamic acid/glutamine, aspartic acid/asparagine, glycine, alanine, arginine, proline, and leucine/isoleucine. Some of these amino acids are charged, providing the biosurfactant extract with an amphoteric characteristic. Therefore, aspartic acid and glutamic acid possess a negative charge, and glycine is amphoteric, presenting a negative or positive charge depending on the $\mathrm{pH}$ of the medium [1]. Regarding its function as a preservative, it possesses antimicrobial activity against bacteria and fungus [3,4]; moreover, the biosurfactant from CSL is non-cytotoxic at a concentration of $1 \mathrm{~g} / \mathrm{L}$ [14]. It is able to increase the solubilization in the water of active principles used in agrochemical formulations [15], and it is biodegradable with a $\mathrm{t}_{1 / 2}$ lower than 15 days between $20-30{ }^{\circ} \mathrm{C}$ at $\mathrm{pH} 6$ [16]. Consequently, this biosurfactant extract could be an interesting alternative to chemically synthetized preservatives and coating agents for prolonging the shelf-life of fruits from harvest to final consumption, which is one of the major problems in this industry. Furthermore, Scalzini et al. [17] studied the effect of this biosurfactant extract during the maceration of two red wine grape varieties (Vitis vinifera L. cv. Aglianico and Cabernet sauvignon) and observed that the biosurfactant extract obtained from CSL improved peel extraction, giving more stable compounds during the maceration process of red wine.

However, the major use of this biosurfactant extract could be related to its use as a preservative or coating agent in fruits postharvest to increase their shelf-life, although, before the addition of the biosurfactants to fruits, it is necessary to study the effect of these surface-active compounds on the physical properties of the selected fruits and evaluate their appeal. In the literature, works that study the effect of biosurfactants on the physical properties and appearance of fruits do not exist.

Physical deterioration of fruits begins the moment they are harvested, with some exceptions, rendering them less acceptable to consumers. Large fruit size, color, blemish-free, or non-roughness are parameters that determine the attractiveness of the appearance of fruits [18]. Nevertheless, during storage, the surface texture changes to a rather shriveled and mate appearance, primarily due to water loss [19]. Thus, edible coatings and preservatives play an important role in increasing the storage time of fruits and vegetables [20].

Hence, in this work, grapes were coated with a solution containing the biosurfactant extract obtained from CSL and compared with non-coated grapes. The evaluation of the grapes included morphological surface analysis (roughness, area, perimeter, minor and major axis) as well as a surface-wetting characterization using contact angle measurements.

\section{Materials and Methods}

\subsection{Biosurfactant Extraction from Corn Steep Liquor}

Biosurfactant extract was obtained from CSL using the procedure established in previous works $[10,21]$. CSL was provided by the FeedStimulants company, and it was subjected to an extraction process with ethyl acetate at room temperature $\left(25^{\circ} \mathrm{C}\right)$ for 45 min using a CSL:ethyl acetate ratio of 1:3 (v/v). After extraction, the organic phase was decanted overnight and separated from the aqueous phase. The biosurfactant extract was recovered from the organic phase by vacuum distillation, and the ethyl acetate was saved 
for a subsequent extraction process. In order to corroborate the surface-active properties of the extract, it was dissolved in distilled water (around $1 \mathrm{~g} / \mathrm{L}$ ), and the decrease in the surface tension of the aqueous solution was measured by using a Krüss K20 EasyDyne tensiometer with a $1.9 \mathrm{~cm}$ platinum Wilhelmy plate (Krüss GmbH, Hamburg, Germany). The minimum surface tension and its critical micellar concentration (CMC) were obtained.

\subsection{Treatment of Grapes with Biosurfactant Extract Solution}

Grapes (Autumn crisp) were obtained from a local market (Vigo, Galicia, Spain). From the batches of grapes, two grapes of similar characteristics, color, size, and general state of ripeness were selected. Grapes were washed with distilled water, and one grape was submerged in an aqueous solution containing $1 \mathrm{~g} / \mathrm{L}$ of biosurfactant extract solution for $1 \mathrm{~min}$ (see Figure 1). For comparative purposes, the other grape was also submerged in water in the absence of the biosurfactant extract. Both types of grapes (coated with biosurfactant extract and non-coated) were dried before analysis in an extraction hood at room temperature $\left(\sim 20^{\circ} \mathrm{C}\right)$. The changes in the morphology of the grapes were followed for 11 days.

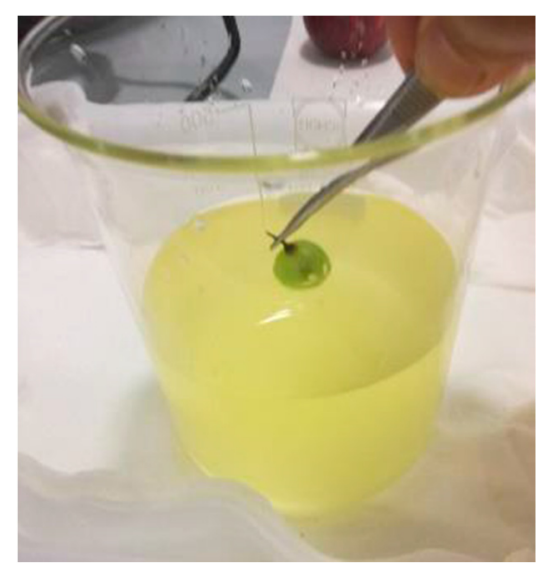

Figure 1. Biosurfactant extract solution for the coating treatment of grapes.

\subsection{Morphological Analysis of Grapes}

Morphological analysis of grapes was carried out using an optical DVM 2500 microscope. 2D images were obtained using $20 \times$ magnification and a $0.3 \times$ intermediate lens (adapter), which provides a field of view of $51 \times 38 \mathrm{~mm}^{2}$. Irfan View 64 (4.56) and IMAGE TOOL $(V)$ software were used for image processing. The 2D images were contrasted and passed to black and white. For this analysis, two grapes with the same grade of maturation were attached to a foam rubber support in order to avoid changes in the position over time. The variables analyzed were area, perimeter, major axis length, and minor axis length.

In addition, the areal roughness of the grapes was analyzed using a profilometer ALICONA IF equipped with an IF-Laboratory measurement module 5.4, providing 2D and $3 \mathrm{D}$ true images at the high macro, micro, and nano level. The equipment uses 3D algorithms and converts it in a single 3D data set to obtain different areal roughness parameters based on the ISO 25178-1 [22,23] as follows: arithmetic mean height of the surface (Sa); root mean square of the surface (Sq); maximum peak height of the surface (Sp); maximum pit height of the surface (Sv); maximum height of the surface (Sz); the ten-point height of the surface (S10z); skewness of the surface (SsK); kurtosis of the surface (Sku); root mean square gradient of the surface (Sdq); and developed interfacial area ratio of the surface (Sdr). Five random zones were spread across for each selected grape (non-coated and coated) and analyzed with an optical profilometer. Images of focus variation were taken using the $50 \times$ lens, which provides a field of view of $400 \times 400 \mathrm{~nm}^{2}$, allowing details of the topography, shape, and texture of the surface of the samples to be observed. 


\subsection{Contact Angle Measurements}

Contact angle $(\theta)$ measurements were carried out with a portable See SYSTEM E instrument. The included software enables the calculation of the surface energy based on the most often used models: Owens-Wendt-Rable-Kaeble, Lifshitz-van der Waals/acid-base, Li-Neumann, Kwok-Neumann, Wu Equation of State, and Zisman. Regression variants of Owens-Wendt and acid-base models are also supported. Additionally, the instrument is provided with a color UVC camera: color 2 Mpix $(1600 \times 1200)$ UVC camera with a high-resolution glass objective lens, which captures high-resolution images of the analyzed drops on the surface of the grapes. Ultrapure Water Type I was used as a surface contact liquid. A drop of $3 \mu \mathrm{L}$ was added to the grape surface, and the contact angle was measured. Six individual coated grapes were used to measure the contact angle, in six random zones at different storage times $(1,3,5,9$, and 11 days), since after each measurement, the grapes were discharged. For comparative purposes, the study also included non-coated grapes.

\subsection{Statistical Analysis}

Statistical analyses were performed by means of the SPSS 24.0 Statistics software (IBM Corporation, Armonk, NY, USA). Among the roughness parameters, Sa and Sq were selected as the two most representative ones for the statistical study. The boxplots were performed in order to get a better interpretation of the results. Otherwise, contact angle measurements were compared by the T-test $(p=0.05)$ for pair of data in order to establish significant differences between them.

\section{Results and Discussion}

\subsection{Effect of Biosurfactant Extract on the Grape Morphology}

The overall objective of the work was to visualize micro-morphological changes in the grape peel during storage when treated with a biosurfactant solution (coated grapes) or untreated (non-coated grapes). Therefore, grapes were coated with a biosurfactant extracted from CSL in order to evaluate the effect of this bioactive extract on the peel surface of the grapes. This biosurfactant extract possesses a CMC of $306.5 \mathrm{mg} / \mathrm{L}$, and it is able to reduce the surface tension of water to $43.8 \mathrm{mN} / \mathrm{m}$ [3]. The grapes were coated with a solution of this biosurfactant extract at a concentration of $1 \mathrm{~g} / \mathrm{L}$ in order to achieve a bactericide concentration determined in previous work [2].

Figure 2 shows the area, perimeter, major axis length, and minor axis length of coated grapes and non-coated grapes at different storage times.

It was observed that coated grapes underwent fewer alterations in these parameters than non-coated grapes. For instance, the area of the non-coated grapes decreased $12.3 \%$ after 11 days of storage, whereas the coated grapes decreased $10.0 \%$, although the major difference was noticed in the major axis and minor axis length. In the coated grapes, the major and minor axis decreased $3.8 \%$ and $5.0 \%$, respectively, whereas the non-coated grapes decreased $6.3 \%$ and $7.6 \%$, respectively. It can be speculated that the biosurfactant extract prevents or reduces water loss in grapes, thus maintaining the shape of the grapes for a greater period of time than non-coated grapes.

Additionally, a morphological study that includes the evaluation of grape roughness was carried out. Tables 1 and 2 include the roughness parameters obtained for the two scenarios, taking into consideration roughness and shape or only roughness, respectively, following the ISO 25178-1 [23]. 


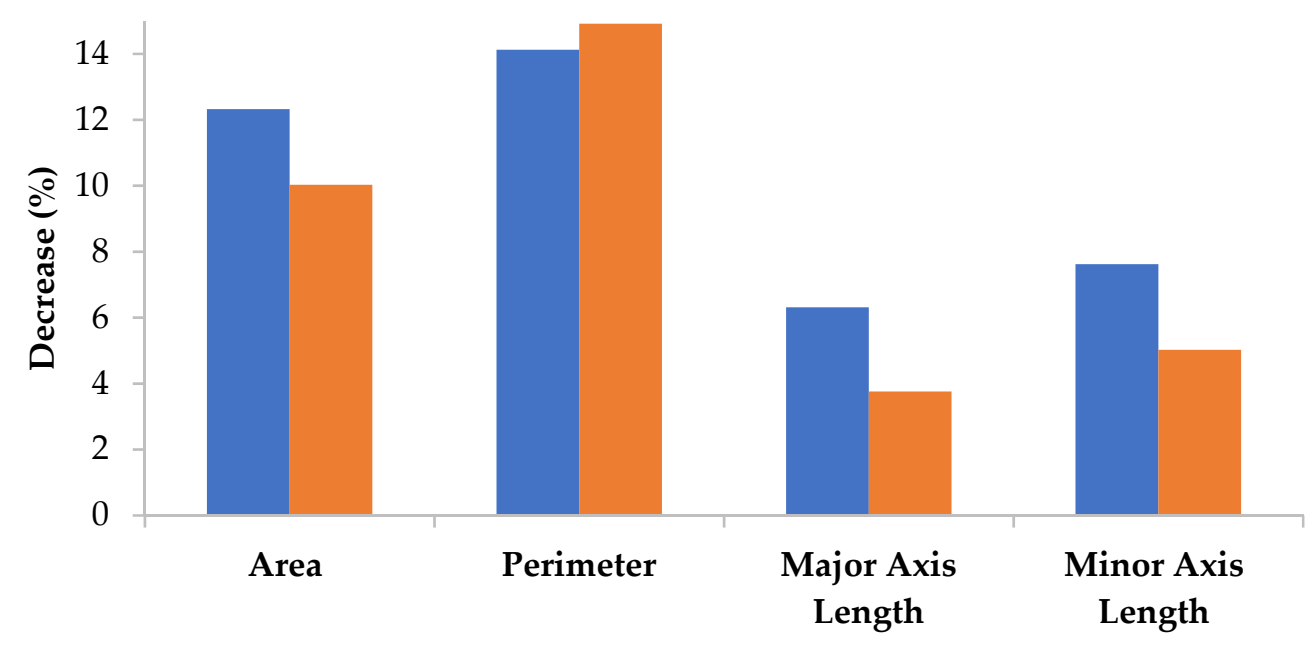

Non-coated grapes $\square$ Coated grapes

Figure 2. Changes produced in the size of grapes at different storage times.

Table 1. Roughness parameters for non-coated and coated grapes without eliminating the shape effect.

\begin{tabular}{|c|c|c|c|c|c|c|}
\hline \multicolumn{7}{|c|}{ NON-COATED GRAPES (FINE STRUCTURE + SHAPE) } \\
\hline Parameter & Units & 1 Day & 3 Days & 5 Days & 9 Days & 11 Days \\
\hline Sa & $\mathrm{nm}$ & $960.20 \pm 116.08$ & $1764.82 \pm 908.96$ & $6866.36 \pm 2551.66$ & $7071.60 \pm 1996.39$ & $6910.16 \pm 2145.21$ \\
\hline Sq & $\mathrm{nm}$ & $1166.55 \pm 161.17$ & $2150.18 \pm 1002.70$ & $8406.54 \pm 3038.88$ & $8833.72 \pm 2502.39$ & $8666.92 \pm 2752.21$ \\
\hline Sp & $\mu \mathrm{m}$ & $3.75 \pm 1.96$ & $5.97 \pm 2.76$ & $22.65 \pm 14.44$ & $15.47 \pm 1.86$ & $15.98 \pm 2.31$ \\
\hline Sv & $\mu \mathrm{m}$ & $8.43 \pm 4.20$ & $11.29 \pm 7.71$ & $25.04 \pm 9.15$ & $34.07 \pm 9.70$ & $28.75 \pm 11.91$ \\
\hline $\mathrm{Sz}$ & $\mu \mathrm{m}$ & $12.18 \pm 5.38$ & $17.26 \pm 10.15$ & $47.69 \pm 21.54$ & $49.55 \pm 10.30$ & $44.73 \pm 13.14$ \\
\hline S10z & $\mu \mathrm{m}$ & $10.87 \pm 4.57$ & $14.10 \pm 7.34$ & $38.87 \pm 18.27$ & $46.05 \pm 11.15$ & $37.82 \pm 7.10$ \\
\hline Ssk & & $-0.36 \pm 0.22$ & $-0.37 \pm 0.39$ & $-0.30 \pm 0.51$ & $-0.82 \pm 0.51$ & $-0.61 \pm 0.46$ \\
\hline Sku & & $3.86 \pm 2.08$ & $3.33 \pm 1.10$ & $2.62 \pm 0.33$ & $3.96 \pm 1.83$ & $3.02 \pm 0.45$ \\
\hline Sdq & & $0.22 \pm 0.15$ & $0.22 \pm 0.14$ & $0.39 \pm 0.27$ & $0.34 \pm 0.14$ & $0.29 \pm 0.06$ \\
\hline Sdr & & $2.39 \pm 2.79$ & $2.65 \pm 2.91$ & $7.16 \pm 8.28$ & $5.55 \pm 3.67$ & $4.22 \pm 1.70$ \\
\hline \multicolumn{7}{|c|}{ COATED GRAPES (FINE STRUCTURE + SHAPE) } \\
\hline Sa & $\mathrm{nm}$ & $1145.55 \pm 63.39$ & $885.65 \pm 126.08$ & $1021.05 \pm 243.30$ & $2696.16 \pm 935.96$ & $3803.46 \pm 1056.51$ \\
\hline $\mathrm{Sq}$ & $\mathrm{nm}$ & $1206.95 \pm 166.54$ & $1077.16 \pm 143.59$ & $1231.65 \pm 285.29$ & $3344.78 \pm 1285.49$ & $4681.28 \pm 1268.89$ \\
\hline Sp & $\mu \mathrm{m}$ & ND* & $2.53 \pm 0.45$ & $2.65 \pm 0.53$ & $6.75 \pm 1.56$ & $8.13 \pm 1.50$ \\
\hline Sv & $\mu \mathrm{m}$ & $\mathrm{ND} *$ & $3.98 \pm 0.60$ & $4.17 \pm 0.71$ & $13.51 \pm 10.91$ & $17.41 \pm 4.23$ \\
\hline $\mathrm{Sz}$ & $\mu \mathrm{m}$ & $\mathrm{ND}^{*}$ & $6.51 \pm 1.04$ & $6.83 \pm 1.15$ & $20.26 \pm 11.71$ & $25.54 \pm 5.59$ \\
\hline $\mathrm{S} 10 \mathrm{z}$ & $\mu \mathrm{m}$ & ND* & $6.14 \pm 1.03$ & $6.10 \pm 1.04$ & $15.97 \pm 5.30$ & $22.31 \pm 4.95$ \\
\hline Ssk & & $-0.78 \pm 0.44$ & $-0.47 \pm 0.12$ & $-0.34 \pm 0.18$ & $-0.66 \pm 0.50$ & $-0.70 \pm 0.27$ \\
\hline Sku & & $1.36 \pm 0.71$ & $2.74 \pm 0.20$ & $2.50 \pm 0.24$ & $3.19 \pm 1.62$ & $3.01 \pm 0.38$ \\
\hline Sdq & & $0.09 \pm 0.03$ & $0.08 \pm 0.02$ & $0.07 \pm 0.01$ & $0.13 \pm 0.03$ & $0.16 \pm 0.02$ \\
\hline Sdr & & $0.43 \pm 0.27$ & $0.30 \pm 0.14$ & $0.22 \pm 0.06$ & $0.87 \pm 0.32$ & $1.29 \pm 0.24$ \\
\hline
\end{tabular}

$\mathrm{ND}^{*}=$ not determined. 
Table 2. Roughness parameters for non-coated and coated grapes eliminating the shape effect.

\begin{tabular}{ccccccc}
\hline \multicolumn{7}{c}{ NON-COATED GRAPES (FINE STRUCTURE) } \\
\hline Parameter & Units & $\mathbf{1}$ Day & 3 Days & 5 Days & 9 Days & 11 Days \\
\hline Sa & $\mathrm{nm}$ & $232.89 \pm 90.37$ & $403.41 \pm 72.26$ & $792.24 \pm 114.51$ & $1066.72 \pm 388.53$ & $959.62 \pm 265.49$ \\
Sq & $\mathrm{nm}$ & $319.46 \pm 128.15$ & $546.19 \pm 113.88$ & $1023.26 \pm 146.70$ & $1347.96 \pm 519.25$ & $1194.56 \pm 306.42$ \\
Sp & $\mu \mathrm{m}$ & $3.14 \pm 2.42$ & $4.88 \pm 3.22$ & $13.08 \pm 20.09$ & $5.36 \pm 2.15$ & $4.77 \pm 0.54$ \\
Sv & $\mu \mathrm{m}$ & $6.11 \pm 5.12$ & $8.64 \pm 8.58$ & $13.10 \pm 11.15$ & $7.76 \pm 3.63$ & $4.37 \pm 0.97$ \\
Sz & $\mu \mathrm{m}$ & $9.25 \pm 7.19$ & $13.52 \pm 11.74$ & $26.18 \pm 29.01$ & $13.12 \pm 5.29$ & $9.14 \pm 1.23$ \\
S10z & $\mu \mathrm{m}$ & $7.08 \pm 5.19$ & $10.03 \pm 7.08$ & $19.15 \pm 25.37$ & $11.31 \pm 5.05$ & $8.32 \pm 1.26$ \\
Ssk & & $-1.28 \pm 2.75$ & $-1.01 \pm 1.41$ & $-0.34 \pm 1.01$ & $-0.15 \pm 0.48$ & $0.12 \pm 0.39$ \\
Sku & & $37.74 \pm 37.32$ & $46.10 \pm 76.60$ & $16.48 \pm 25.37$ & $3.66 \pm 0.92$ & $3.28 \pm 0.78$ \\
Sdq & & $0.20 \pm 0.18$ & $0.21 \pm 0.15$ & $0.33 \pm 0.29$ & $0.26 \pm 0.14$ & $0.21 \pm 0.04$ \\
Sdr & & $2.41 \pm 3.40$ & $2.42 \pm 2.87$ & $5.61 \pm 8.05$ & $3.15 \pm 2.82$ & $2.26 \pm 0.82$ \\
& & & COATED GRAPES (FINE STRUCTURE) & & \\
Sa & $\mathrm{nm}$ & $140.42 \pm 15.39$ & $159.82 \pm 27.65$ & $188.74 \pm 27.99$ & $424.71 \pm 54.13$ & $538.46 \pm 31.17$ \\
Sq & $\mathrm{nm}$ & $181.59 \pm 21.57$ & $208.71 \pm 41.70$ & $238.72 \pm 34.39$ & $537.53 \pm 64.68$ & $691.43 \pm 52.35$ \\
Sp & $\mu \mathrm{m}$ & $1.31 \pm 0.22$ & $1.42 \pm 0.44$ & $1.41 \pm 0.34$ & $2.12 \pm 0.62$ & $3.18 \pm 0.71$ \\
Sv & $\mu \mathrm{m}$ & $0.84 \pm 0.06$ & $1.39 \pm 1.10$ & $0.98 \pm 0.15$ & $3.56 \pm 2.89$ & $3.59 \pm 0.89$ \\
Sz & $\mu \mathrm{m}$ & $2.15 \pm 0.27$ & $2.81 \pm 1.27$ & $2.39 \pm 0.42$ & $5.68 \pm 2.75$ & $6.76 \pm 0.71$ \\
S10z & $\mu \mathrm{m}$ & $1.77 \pm 0.30$ & $2.38 \pm 1.17$ & $2.03 \pm 0.33$ & $4.49 \pm 1.15$ & $5.98 \pm 0.49$ \\
Ssk & & $0.66 \pm 0.20$ & $0.33 \pm 0.75$ & $0.30 \pm 0.19$ & $-0.23 \pm 0.24$ & $-0.33 \pm 0.32$ \\
Sku & & $4.12 \pm 0.55$ & $6.78 \pm 4.86$ & $3.47 \pm 0.42$ & $4.13 \pm 1.49$ & $4.03 \pm 0.85$ \\
Sdq & & $0.07 \pm 0.01$ & $0.07 \pm 0.02$ & $0.06 \pm 0.01$ & $0.11 \pm 0.02$ & $0.12 \pm 0.01$ \\
Sdr & & $0.24 \pm 0.06$ & $0.27 \pm 0.13$ & $0.18 \pm 0.06$ & $0.60 \pm 0.15$ & $0.70 \pm 0.07$ \\
\hline
\end{tabular}

In one case, shape and roughness were taken into consideration together to establish these values (see Table 1), and in the other case, a filter was applied to the images in order to eliminate the effect of shape on the roughness values (see Table 2). When shape and roughness are considered together, the values obtained are strongly affected by the cylindrical shape of the grape, as the height $(\mathrm{z})$ values of the shape are much higher than those of the roughness. Therefore, for a more exhaustive study of roughness, the effect of the shape was eliminated (Table 2) and compared with those values where the shape was considered (Table 1).

The most representative parameters for measuring the roughness are the Sa and Sq values, which evaluate the changes in the height differences between points measuring the deformation of the surface, observing that these values from day 3 were always lower in coated grapes compared with non-coated grapes. Roughness can be interpreted based on observing the changes in the fine texture and shape (see Table 1) or just based on fine texture (see Table 2). In both sceneries, coated grapes resist showing changes in roughness for many days, while the untreated grapes quickly showed alterations in the structure of the peel. The roughness changes in the treated grape begin to be noticeable after 9 days when fine texture and shape are considered, while in the non-coated grapes, these significant changes were observed from day 3 , which is an indication that deterioration was much faster in untreated grapes than in treated ones. Hence, coated grapes showed a percentage increase in the roughness starting at values of $332 \%$, whereas non-coated grapes showed a percentage increase of $720 \%$, indicating that deterioration is 2.2 times higher in untreated grapes. The same behavior was observed when only the fine texture was considered, although in this case, the differences between coated and non-coated grapes were lower. Therefore, taking into account the changes only in the fine texture, coated grapes increased their roughness by about $383 \%$, whereas non-coated grapes increased their roughness by about $412 \%$, which indicates a grade of deterioration 1.1 times higher for non-coated grapes in comparison with coated grapes.

On the other hand, Figures 3 and 4 show a boxplot statistical analysis of most representative roughness parameters (Sa and Sq), considering or not considering the effect of shape, respectively. 
(a)

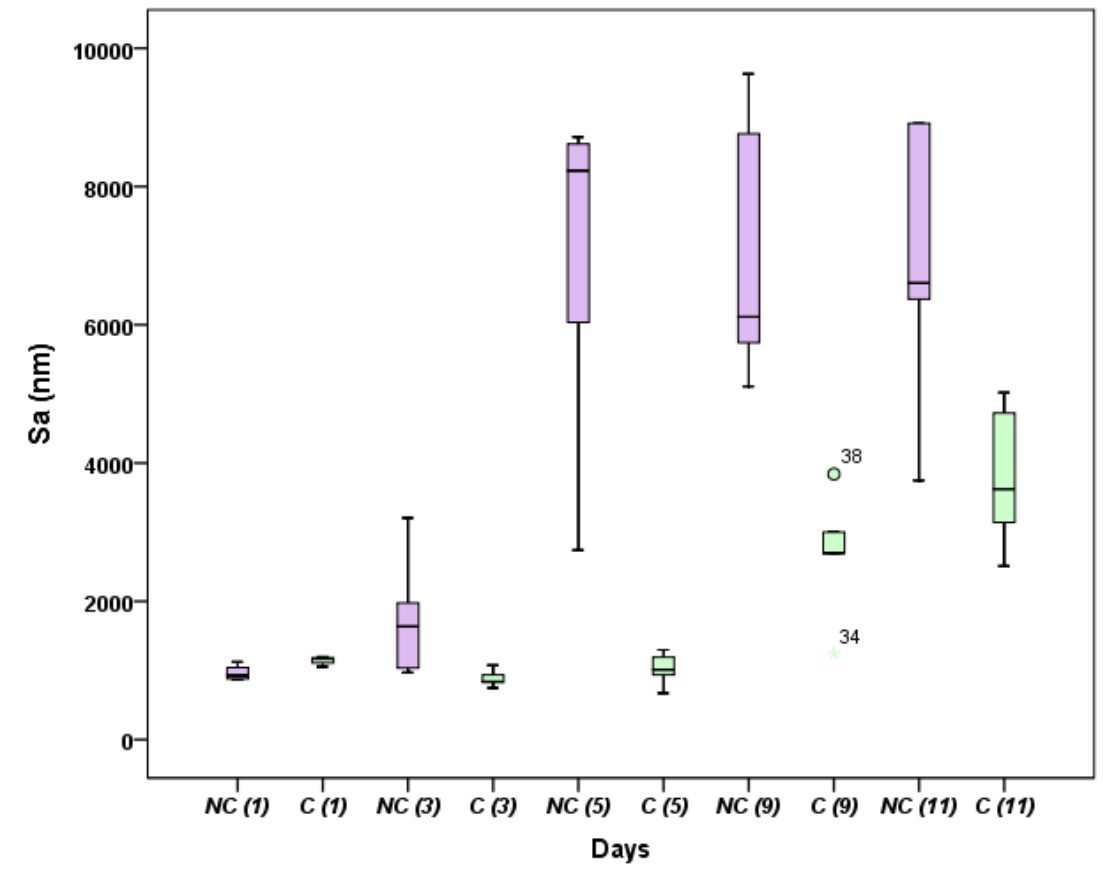

(b)

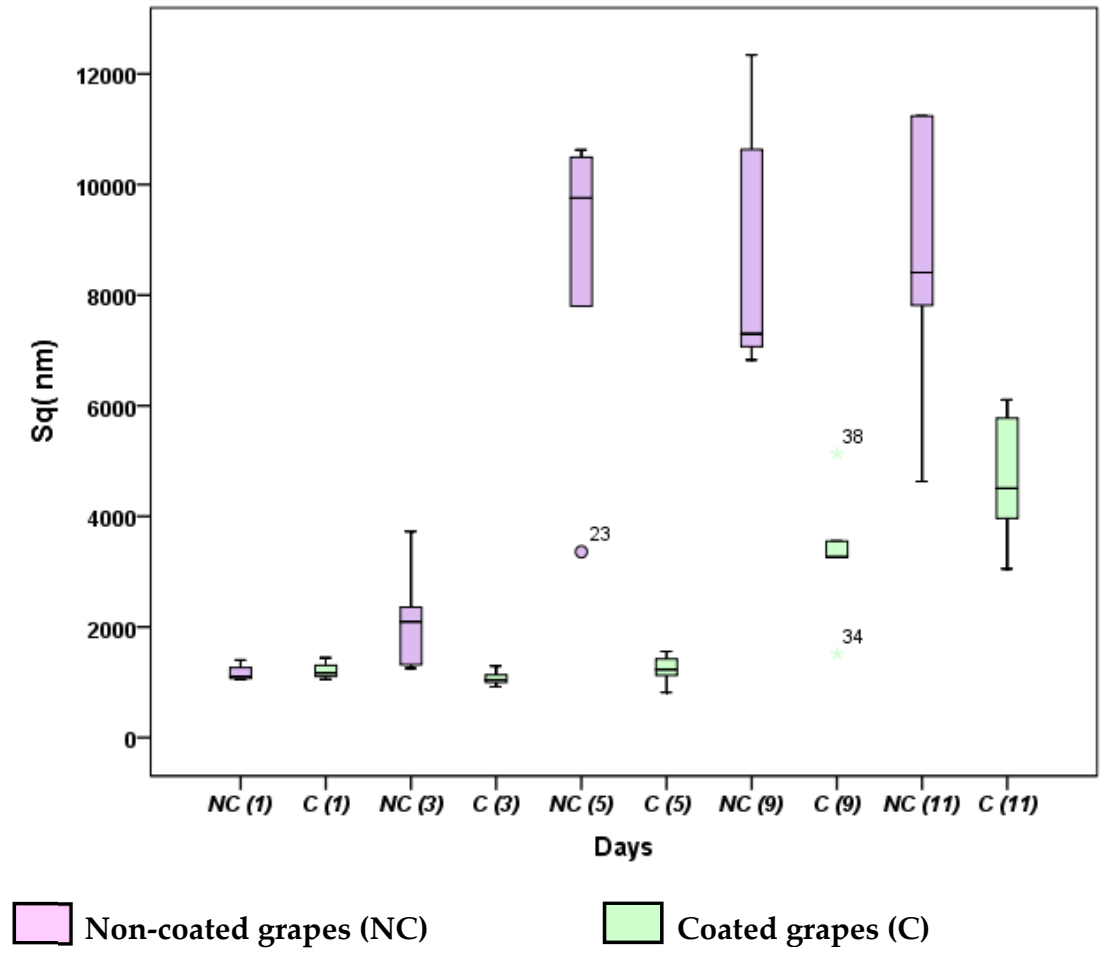

Figure 3. Statistical analysis of Sa (a) and Sq (b), considering fine structure and shape, for non-coated and coated grapes after 11 days of storage represented by boxplots. 
(a)

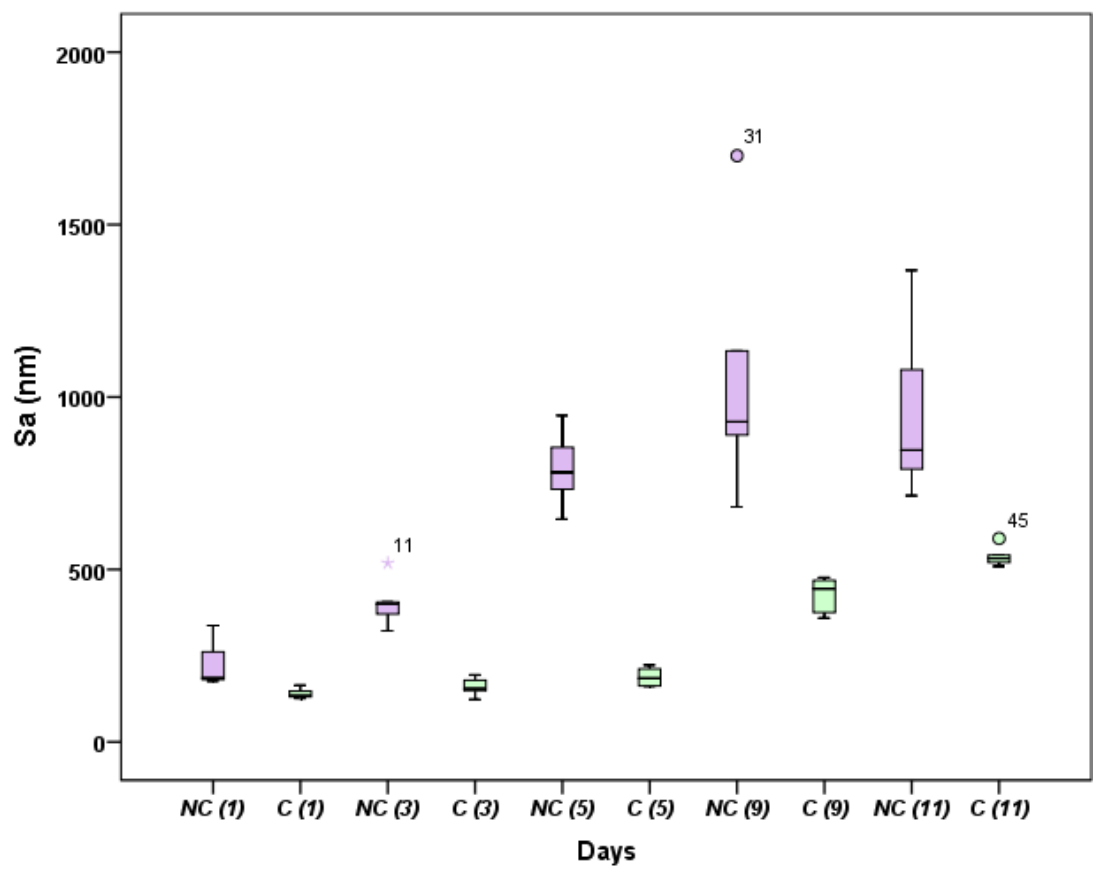

(b)

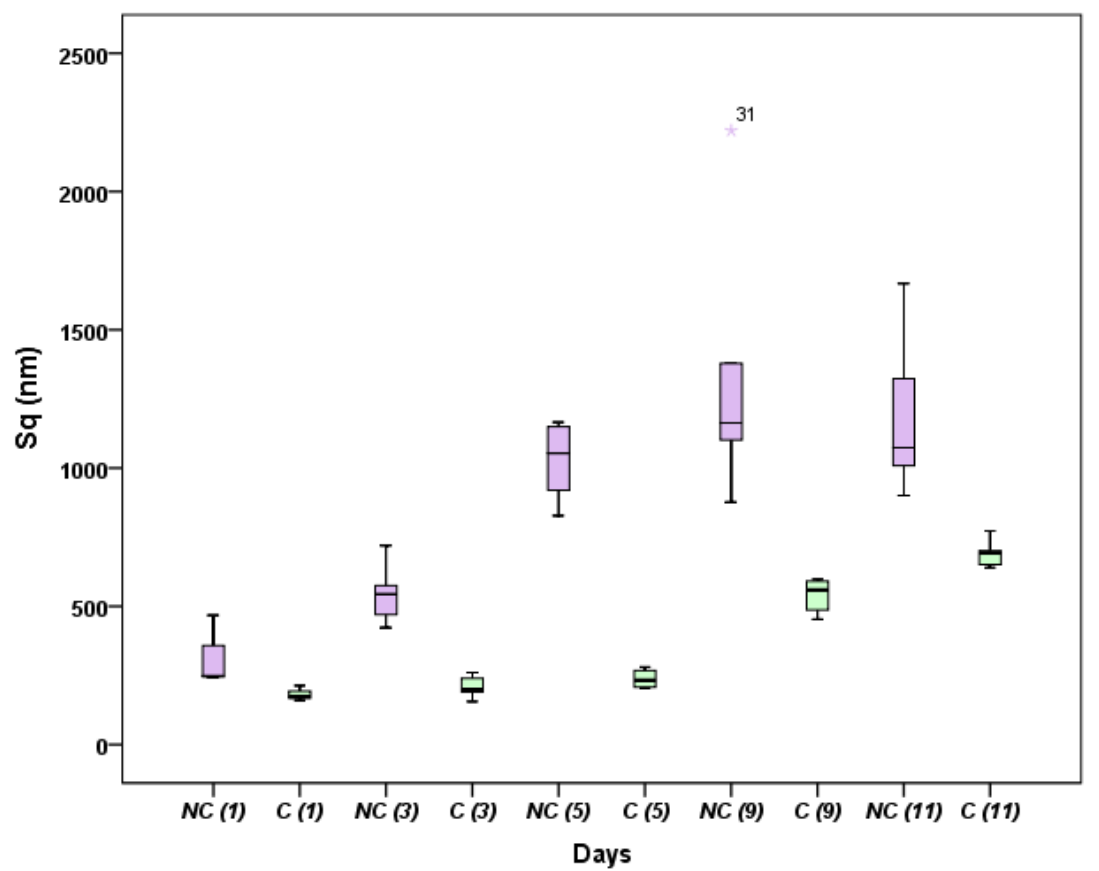

Non-coated grapes (NC)

Coated grapes (C)

Figure 4. Statistical analysis of Sa (a) and Sq (b), only considering fine structure, for non-coated and coated grapes after 11 days of storage represented by boxplots.

As can be seen in Figure 3, when considering fine structure and shape, the boxplot graphs show that on the first day of the study there are no significant differences between the coated and non-coated grapes for both Sa and Sq. Therefore, for the Sq parameter (Figure $3 \mathrm{~b}$ ), the lower $(25 \%)$ and upper $(75 \%)$ percentiles were very similar for the noncoated and coated grapes, with values between 1058-1088 nm for the lower percentile and between 1334-1375 $\mathrm{nm}$ for the upper percentile. The dispersion of the results in this parameter was also very similar, with an interquartile range of $275 \mathrm{~nm}$ for the non-coated grapes and $295 \mathrm{~nm}$ for the coated grapes. For the Sa parameter (Figure 3a), relatively 
similar behavior is observed, on the first day of the assay, in relation to the upper and lower percentiles of the non-coated and coated grapes, although the dispersion of the results in the non-coated grapes was slightly higher than in the coated grapes, with interquartile range values of 211 and $110 \mathrm{~nm}$, respectively. After 3 days, a significant difference was detected between the non-coated and coated grapes, for the Sa and Sq parameters. The noncoated grapes gave higher roughness values than those observed in the coated grapes; in fact, for the Sq parameter (Figure 3b), the lower percentile of the non-coated grapes $(1286 \mathrm{~nm})$ gave a higher value than the upper percentile of the coated grapes $(1214 \mathrm{~nm})$. Similar behavior was observed for the Sa parameter (Figure 3a), since the lower percentile of the non-coated grapes $(1002 \mathrm{~nm})$ was similar to the upper percentile of the coated grapes $(1005 \mathrm{~nm})$, indicating that $50 \%$ of the results of the non-coated grapes were higher than those of the coated grapes. Furthermore, for the non-coated grapes, a greater dispersion of data was observed for Sa and Sq, with interquartile ranges (1589 nm for Sa and $1755 \mathrm{~nm}$ for Sq) much higher than those obtained for the coated grapes (218 nm for Sa and $255 \mathrm{~nm}$ for Sq). In addition, for days 5, 9, and 11, a notable increase of the variables Sa and Sq was noticed in the non-coated grapes, whereas in coated grapes the increase in roughness was moderated. In addition, from day 5 to 11, non-coated grapes showed lower percentiles ranging between $4387-5425 \mathrm{~nm}$ for Sa, with the upper percentiles between $8665-9196 \mathrm{~nm}$, indicating a great similarity of the results. As well, the Sq parameter showed similar behavior for the non-coated grapes, with the lower percentiles ranging between 5580 and $6947 \mathrm{~nm}$ and with the upper percentiles ranging between 10,558-11,487 nm. Regarding coated grapes, a progressive increase in roughness was observed, for both Sa and Sq parameters, with a progressive increase in the upper percentiles although less strong than in non-coated grapes. The dispersion of the results was higher in the non-coated grapes than in the coated grapes, with interquartile ranges for non-coated grapes oscillating between 3771-4277 and 4540-5015 nm, for the Sa and Sq parameters, respectively. In contrast, in the coated grapes, the interquartile ranges were considerably smaller, with values between 443-2044 and 518-2435 $\mathrm{nm}$ for the Sa and Sq variables, respectively.

On other hand, Figure 4 shows the boxplot graphs for grape roughness, considering only fine structure. It was observed that non-coated grapes increased Sa and Sq values progressively from day 1 to day 5 , where the upper percentile values of each day were always lower than the lower percentiles of the following day, for both Sa and Sq parameters (Figure $4 a, b$ ). However, on days 9 and 11 a stagnation in the increase of roughness was observed, with Sa and Sq values being quite similar between days 5 and 11. In fact, for days 5 to 11 , the lower percentile values for the variable Sa were always between $690-785 \mathrm{~nm}$ and for the upper percentile between $900-1417 \mathrm{~nm}$. In parallel, for the Sq parameter, the lower percentile for day 5 to 11 ranged between $874-989 \mathrm{~nm}$ and the upper percentile was between $1158-1799 \mathrm{~nm}$, which showed a great similarity between the results compared. In relation to the coated grapes, on the first three days $(1,3$, and 5), a very insignificant increase in roughness was observed, considering $\mathrm{Sa}$ and $\mathrm{Sq}$ values. Hence, the lower percentile for Sa ranged between 128-162 nm and that of the Sq variable between 164-206 nm, whereas the upper percentile being between 156-217 $\mathrm{nm}$ for the Sa and between 203-274 nm for Sq. However, a significant increase in roughness was detected from day 5 , where the upper percentile values of each day were always lower than the lower percentiles of the next day. Similarly, to the results shown in Figure 3, where it was considered fine structure and shape, a greater dispersion of Sa and Sq values was observed for non-coated grapes, where it was considered only fine structure (Figure 4), being more prominent between days 5 and 11. In fact, when considering only the fine structure (Figure 4), the interquartile ranges of the variable Sa oscillated between 210-631 for the non-coated grapes, whereas coated grapes gave an interquartile range between $51-105 \mathrm{~nm}$. The same behavior was noticed for the Sq parameter, since the interquartile range of the non-coated grapes was considerably higher (283-810 nm) than that of the coated grapes (68-124 nm).

In overall terms, it can be said that the biosurfactant extract under evaluation protects grape skin against roughness, showing a significant positive effect. 
Additionally, Figure 5a,b show the images obtained for non-coated and coated grapes, respectively, considering only fine texture at different storage times.

(a)

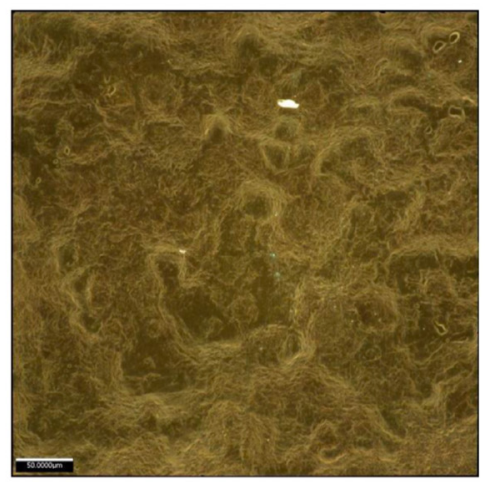

(b)

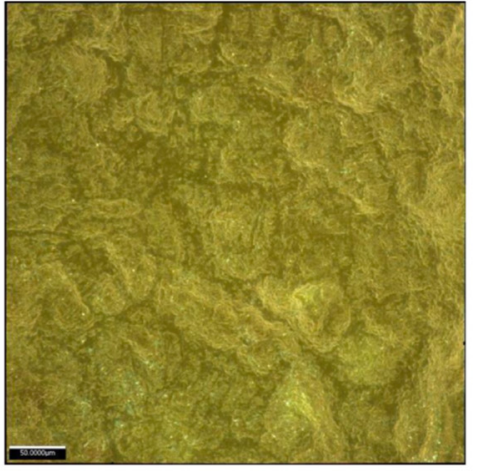

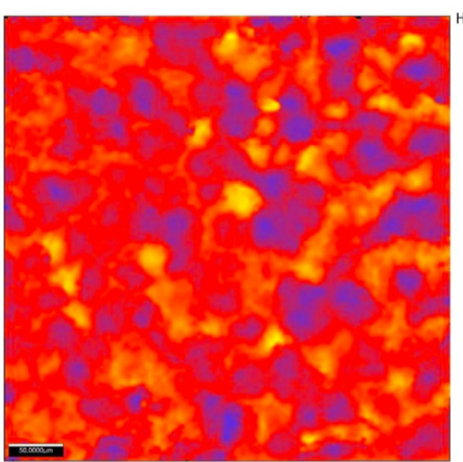
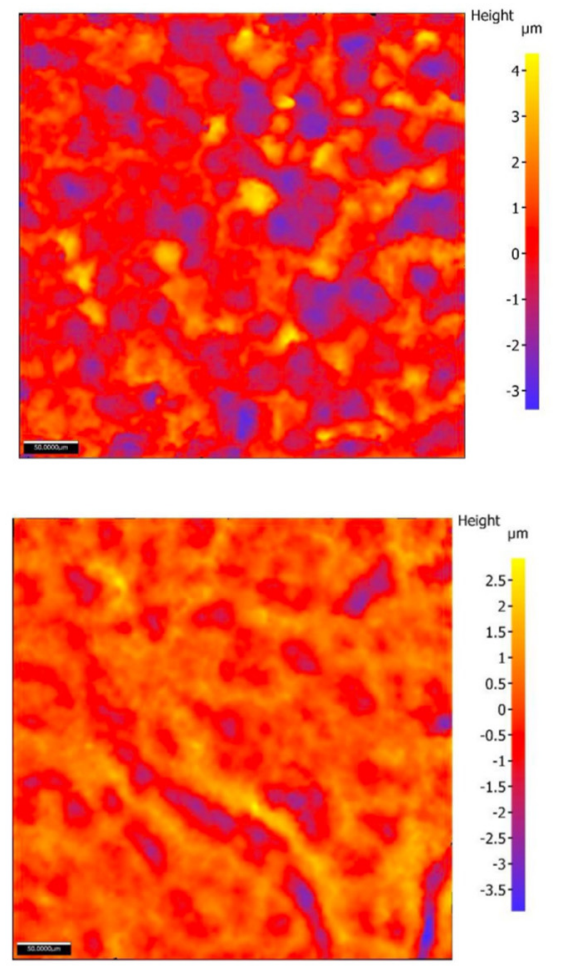

Figure 5. 2D optical real images and topographical maps of non-coated (a) and coated (b) grapes after 11 days of storage, with a field of view of $400 \times 400 \mu \mathrm{m}^{2}$.

The blue or dark zones represent fissures and cavities (right). The greater the proportion of these cavities, more are the changes in height and, therefore, the roughness parameters. It can be noticed that non-coated grapes presented zones with more fissures and cavities, which is in agreement with the data reported in Tables 1 and 2. Also, in the real images (left), more bumps and wrinkles were observed on the surface of the non-coated grapes. The heights in the non-coated grapes were between 4 and $-3 \mu \mathrm{m}$, whereas in the coated grapes, they were between 2.5 and $-3.5 \mu \mathrm{m}$, which indicates that non-coated grapes possess higher numbers of cavities than coated grapes.

\subsection{Effect of Biosurfactant on Contact Angle of Grapes}

Contact angle $(\theta)$ varies depending on the relationship between the different adhesion and cohesion forces between the drop of water and grapes. If the adhesion forces are high, the contact angle that forms between the drop and the surface of the grapes should be less than $90^{\circ}$, as the liquid is attracted by the solid, promoting the liquid expansion on the grape. However, if the attraction forces between the grape surface and the liquid are low, the cohesive hardness promotes liquid contraction on the grape surface. In this case, grapes coated with the biosurfactant extract solution, after one day of storage, gave an average contact angle for a drop of water of about $89.6^{\circ}$, while grapes without treatment gave an average contact angle of $81.1^{\circ}$. The contact angle of the grape surface is similar to the contact angle of apple $\left(81.0^{\circ}\right)$ and lower than the contact angle of tomato $\left(95.0^{\circ}\right)$ and persimmon $\left(88.0^{\circ}\right)$, as reported by Sapper et al. [24]. When grapes were coated with the biosurfactant extract solution, an increase in the hydrophobicity of the grape surface was observed, which decreases its wettability. The biosurfactant extract evaluated in this work is composed of $\mathrm{C} 16-\mathrm{C} 18$ fatty acids and amino acids with hydrophobic side chains, including alanine and leucine/isoleucine, which could explain the increase in the hydrophobicity of the grape surface with the addition of the biosurfactant extract. 
Figure 6 shows the values of contact angle for a drop of water when it is added on the surface of grapes coated with biosurfactant after different storage times.

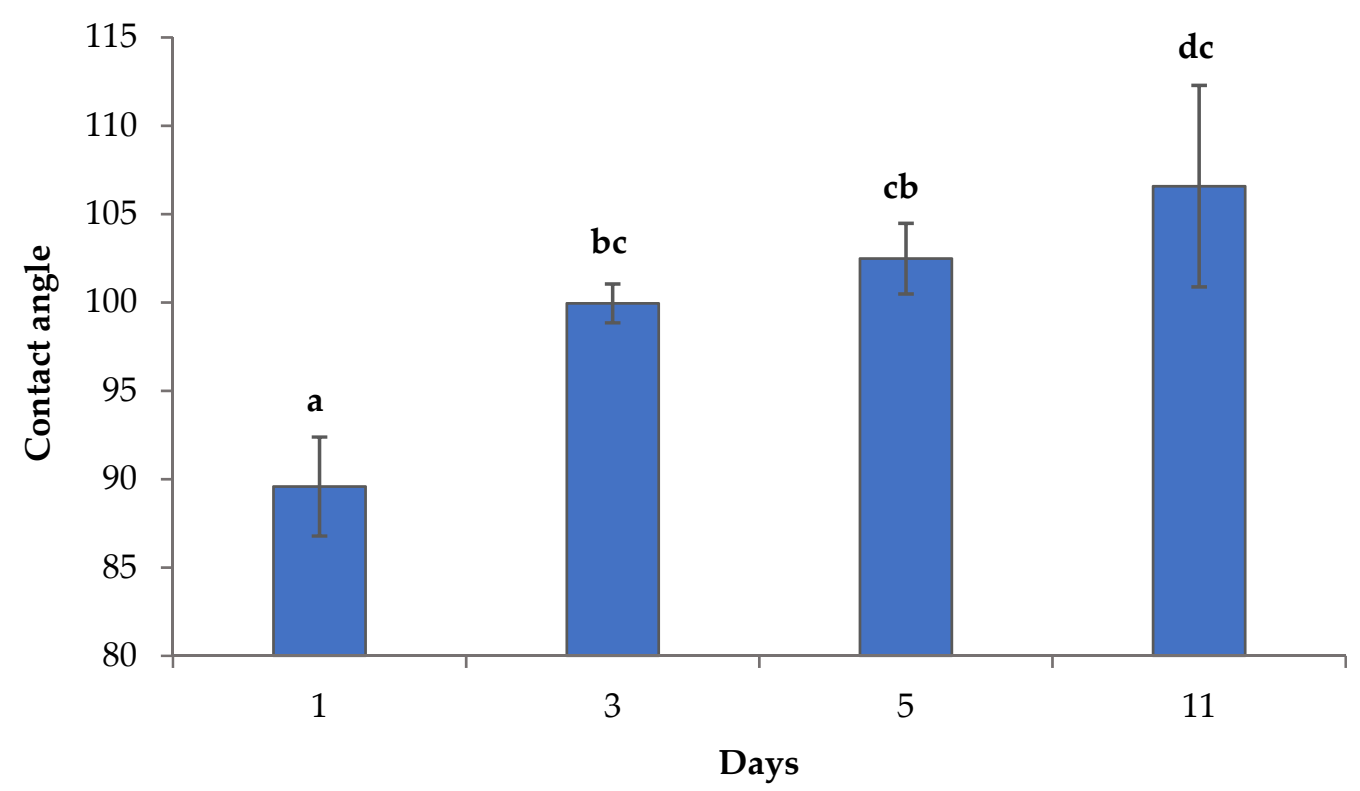

Figure 6. Contact angle $(\theta)$ of coated grapes at different storage times. Different Latin letters indicate significant differences among days ( $T$-test; $p=0.05)$.

Furthermore, Figure 7 shows the images of the drop of water on the grape surface under different conditions and storage times, which show the increase in the roughness with the storage time. After applying the T-test to pairs of data, no significant differences $(p=0.05)$ were observed between 3-5 days and also between 5-11 days.

(a)
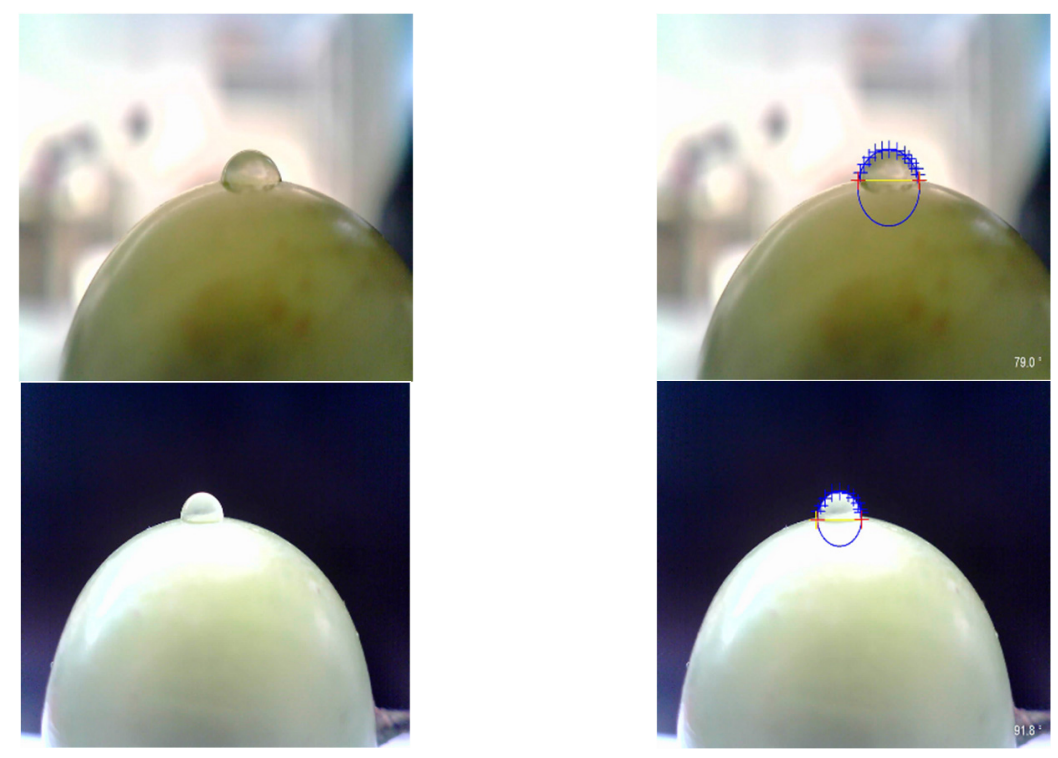

Figure 7. Cont. 
(c)
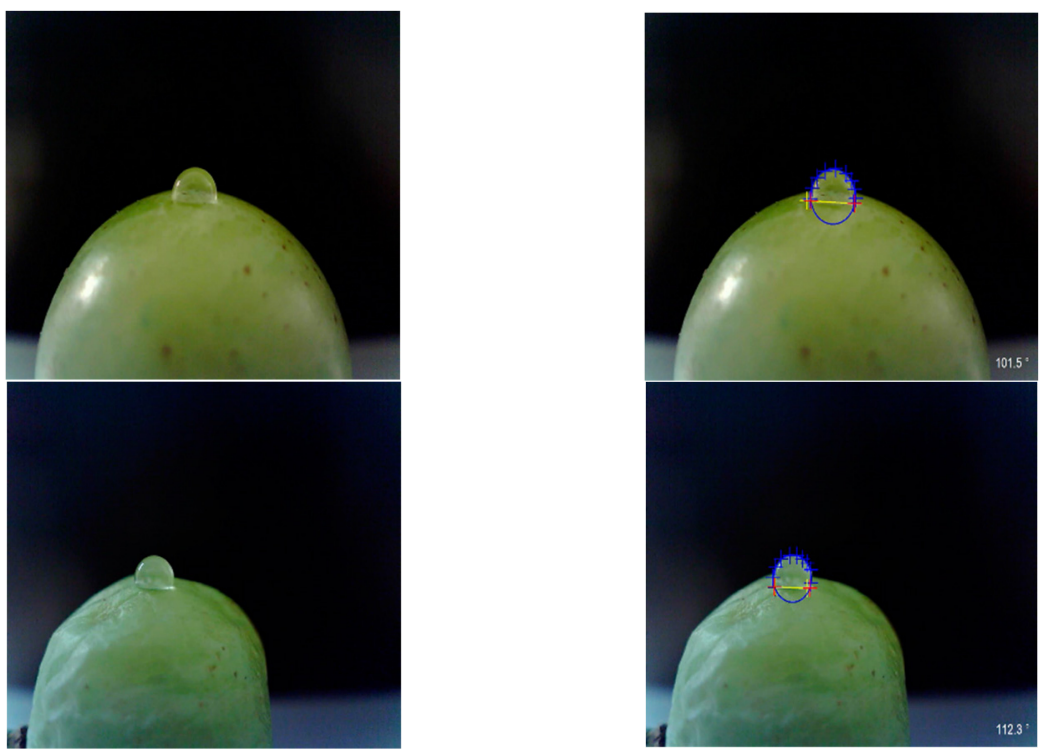

Figure 7. Images of grapes selected to measure the contact angle $(\theta)$ : (a) non-coated grapes after 1 day of storage; (b) coated grapes after 1 day of storage; (c) coated grapes after 5 days of storage; and $(\mathbf{d})$ coated grapes after 11 days of storage.

It was observed that grapes with a longer storage time had a higher contact angle because the contact angle can be affected by the surface roughness. Hence, Wenzel et al. [25] found that adding roughness to a hydrophilic surface increases its wettability and reduces the contact angle. However, if a surface is chemically hydrophobic, it would increase its hydrophobic character by increasing its roughness. These results are in agreement with the increase in the contact angle observed in those coated grapes with more storage time, which possess a higher roughness. For instance, coated grapes after 11 days of storage had an average contact angle of $106.6^{\circ}$.

\section{Conclusions}

The biosurfactant extract obtained from corn steep liquor increases the shelf-life of grapes delaying the deterioration of the physical structure. Changes in shape and roughness were produced to a lower extent in coated grapes in comparison with non-coated grapes. Moreover, the water contact angle measurements showed that the biosurfactant extract produced higher contact angle reducing the wettability of the grape surface. In further works, it will be necessary to test if the decrease in roughness and the increase of hydrophobicity in coated grapes reduce the microbial contamination of coated grapes in comparison to non-coated grapes.

Author Contributions: Conceptualization, A.M.-A., A.L.-P., L.R.-L., B.P.-C., X.V., A.B.M., and J.M.C.; methodology, A.M.-A., A.L.-P. and L.R.-L.; validation, A.M.-A., A.L.-P., L.R.-L., B.P.-C., X.V., A.B.M., and J.M.C.; formal analysis, A.M.-A., X.V., L.R.-L.; investigation, A.M.-A., A.L.-P., L.R.-L., B.P.-C., X.V., A.B.M., and J.M.C.; resources, A.B.M. and J.M.C.; writing-original draft preparation, A.M.-A., X.V., A.B.M., and J.M.C.; writing-review and editing, A.M.-A., X.V., A.B.M., and J.M.C.; visualization, A.M.-A., A.L.-P., L.R.-L., B.P.-C., X.V., A.B.M. and J.M.C.; supervision, B.P.-C., X.V., A.B.M. and J.M.C.; project administration, A.B.M. and J.M.C.; funding acquisition, A.B.M., and J.M.C. All authors have read and agreed to the published version of the manuscript.

Funding: This research was funded by the Spanish Ministry of Economy and Competitiveness (MINECO) under the project RTI2018-093610-B-100, and by the Xunta de Galicia under the project GPC-ED431B 2020/17.

Institutional Review Board Statement: Not applicable.

Informed Consent Statement: Not applicable. 
Data Availability Statement: The data presented in this study is available on request from the corresponding author.

Acknowledgments: A. López-Prieto expresses his gratitude to the University of Vigo for his predoctoral scholarship. X. Vecino thanks the Spanish Ministry of Science and Innovation for her financial support under the project PID2019-103873RJ-I00. The authors would also like to acknowledge C. Serra, from the Center for Scientific and Technological Support to Research (CACTI) of the University of Vigo, for her support in the surface analysis.

Conflicts of Interest: The authors declare no conflict of interest.

\section{References}

1. Rodríguez-López, L.; Rincón-Fontán, M.; Vecino, X.; Cruz, J.M.; Moldes, A. Ionic Behavior Assessment of Surface-Active Compounds from Corn Steep Liquor by Exchange Resins. J. Surfactants Deterg. 2017, 20, 207-217. [CrossRef]

2. López-Prieto, A.; Vecino, X.; Rodríguez-López, L.; Moldes, A.B.; Cruz, J.M. A Multifunctional Biosurfactant Extract Obtained from Corn Steep Water as Bactericide for Agrifood Industry. Foods 2019, 8, 410. [CrossRef] [PubMed]

3. López-Prieto, A.; Vecino, X.; Rodríguez-López, L.; Moldes, A.B.; Cruz, J.M. Fungistatic and Fungicidal Capacity of a Biosurfactant Extract Obtained from Corn Steep Water. Foods 2020, 9, 662. [CrossRef]

4. Ben Khedher, S.; Boukedi, H.; Laarif, A.; Tounsi, S. Biosurfactant Produced by Bacillus Subtilis V26: A Potential Biological Control Approach for Sustainable Agriculture Development. Org. Agric. 2020, 10, 117-124. [CrossRef]

5. Kourmentza, K.; Gromada, X.; Michael, N.; Degraeve, C.; Vanier, G.; Ravallec, R.; Coutte, F.; Karatzas, K.A.; Jauregi, P. Antimicrobial Activity of Lipopeptide Biosurfactants against Foodborne Pathogen and Food Spoilage Microorganisms and Their Cytotoxicity. Front. Microbiol. 2021, 11, 561060. [CrossRef] [PubMed]

6. Mukherjee, S.; Das, P.; Sen, R. Towards Commercial Production of Microbial Surfactants. Trends Biotechnol. 2006, 24, 509-515. [CrossRef] [PubMed]

7. Makkar, R.S.; Cameotra, S.S.; Banat, I.M. Advances in Utilization of Renewable Substrates for Biosurfactant Production. AMB Express 2011, 1, 5. [CrossRef]

8. Vecino, X.; Cruz, J.M.; Moldes, A.B.; Rodrigues, L.R. Biosurfactants in Cosmetic Formulations: Trends and Challenges. Crit. Rev. Biotechnol. 2017, 37, 911-923. [CrossRef]

9. Vecino, X.; Barbosa-Pereira, L.; Devesa-Rey, R.; Cruz, J.M.; Moldes, A.B. Study of the Surfactant Properties of Aqueous Stream from the Corn Milling Industry. J. Agric. Food Chem. 2014, 62, 5451-5457. [CrossRef]

10. Vecino, X.; Barbosa-Pereira, L.; Devesa-Rey, R.; Cruz, J.M.; Moldes, A.B. Optimization of Liquid-Liquid Extraction of Biosurfactants from Corn Steep Liquor. Bioprocess Biosyst. Eng. 2015, 38, 1629-1637. [CrossRef]

11. López-Prieto, A.; Martínez-Padrón, H.; Rodríguez-López, L.; Moldes, A.B.; Cruz, J.M. Isolation and Characterization of a Microorganism That Produces Biosurfactants in Corn Steep Water. CyTA-J. Food 2019, 17, 509-516. [CrossRef]

12. Rodríguez-López, L.; Rincón-Fontán, M.; Vecino, X.; Cruz, J.M.; Moldes, A.B. Extraction, Separation and Characterization of Lipopeptides and Phospholipids from Corn Steep Water. Sep. Purif. Technol. 2020, 248, 117076. [CrossRef]

13. López-Prieto, A.; Rodríguez-López, L.; Rincón-Fontán, M.; Cruz, J.M.; Moldes, A.B. Characterization of Extracellular and Cell Bound Biosurfactants Produced by Aneurinibacillus Aneurinilyticus Isolated from Commercial Corn Steep Liquor. Microbiol. Res. 2021, 242, 126614. [CrossRef]

14. Rodríguez-López, L.; López-Prieto, A.; Lopez-Álvarez, M.; Pérez-Davila, S.; Serra, J.; González, P.; Cruz, J.M.; Moldes, A.B. Characterization and Cytotoxic Effect of Biosurfactants Obtained from Different Sources. ACS Omega 2020, 5, 31381-31390. [CrossRef]

15. López-Prieto, A.; Moldes, A.B.; Cruz, J.M.; Pérez Cid, B. Towards More Ecofriendly Pesticides: Use of Biosurfactants Obtained from the Corn Milling Industry as Solubilizing Agent of Copper Oxychloride. J. Surfactants Deterg. 2020, 23, 1055-1066. [CrossRef]

16. Rodríguez-López, L.; Rincón-Fontán, M.; Vecino, X.; Moldes, A.B.; Cruz, J.M. Biodegradability Study of the Biosurfactant Contained in a Crude Extract from Corn Steep Water. J. Surfactants Deterg. 2020, 23, 79-90. [CrossRef]

17. Scalzini, G.; López-Prieto, A.; Paissoni, M.A.; Englezos, V.; Giacosa, S.; Rolle, L.; Gerbi, V.; Segade, S.R.; Cid, B.P.; Moldes, A.B.; et al. Can a Corn-Derived Biosurfactant Improve Colour Traits of Wine? First Insight on Its Application during Winegrape Skin Maceration versus Oenological Tannins. Foods 2020, 9, 1747. [CrossRef] [PubMed]

18. Stover, E.; Mercure, E.W. The Pomegranate: A New Look at the Fruit of Paradise. HortScience 2007, 42, 1088-1092. [CrossRef]

19. Czieczor, L.; Bentkamp, C.; Damerow, L.; Blanke, M. Non-Invasive Determination of the Quality of Pomegranate Fruit. Postharvest Biol. Technol. 2018, 136, 74-79. [CrossRef]

20. Thompson, A.K. Controlled Atmosphere Storage of Fruits and Vegetables; Wilford, S., Carroll, M., Eds.; CABI: Wallingford, UK, 2010; ISBN 9781845936464.

21. Rodríguez-López, L.; Vecino, X.; Barbosa-Pereira, L.; Moldes, A.B.; Cruz, J.M. A Multifunctional Extract from Corn Steep Liquor: Antioxidant and Surfactant Activities. Food Funct. 2016, 7, 3724-3732. [CrossRef]

22. Marinello, F.; Pezzuolo, A. Application of ISO 25178 Standard for Multiscale 3D Parametric Assessment of Surface Topographies. IOP Conf. Ser. Earth Environ. Sci. 2019, 275, 012011. [CrossRef] 
23. AENOR (Asociación Española de Normalización y Certificación). Geometrical Product Specifications (GPS)—Surface Texture: Areal-Part 1: Indication of Surface Texture; BSI: London, UK, 2016; ISO 25178-1:2016; pp. 1-32.

24. Sapper, M.; Bonet, M.; Chiralt, A. Wettability of Starch-Gellan Coatings on Fruits, as Affected by the Incorporation of Essential Oil and/or Surfactants. LWT-Food Sci. Technol. 2019, 116, 108574. [CrossRef]

25. Wenzel, R.N. Resistance of Solid Surfaces to Wetting by Water. Ind. Eng. Chem. 1936, 28, 988-994. [CrossRef] 